\title{
Erratum to: Robust motion control of a two-wheeled inverted pendulum with an input delay based on optimal integral sliding mode manifold
}

\author{
Yusheng Zhou • Zaihua Wang
}

Published online: 24 May 2016

(C) Springer Science+Business Media Dordrecht 2016

\section{Erratum to: Nonlinear Dyn \\ DOI 10.1007/s11071-016-2811-4}

The authors' names were incorrect in the initial, online publication. The names have been corrected in the online publication, and they are correct in this erratum too.

The online version of the original article can be found under doi:10.1007/s11071-016-2811-4.

Y. Zhou $\cdot$ Z. Wang $(\varangle)$

State Key Laboratory of Mechanics and Control of Mechanical Structures, Nanjing University of Aeronautics and Astronautics, Nanjing 210016, China

e-mail: zhwang@nuaa.edu.cn 